\title{
Therapeutic vaccines for malignant brain tumors
}

\author{
Michael P Gustafson' \\ Keith L Knutson ${ }^{2}$ \\ Allan B Dietz' \\ 'Division of Transfusion Medicine; \\ ${ }^{2}$ Department of Immunology, Mayo \\ Clinic, Rochester, MN, USA
}

\begin{abstract}
Malignant gliomas are the most common and aggressive form of brain tumors. Current therapy consists of surgical resection, followed by radiation therapy and concomitant chemotherapy. Despite these treatments, the prognosis for patients is poor. As such, investigative therapies including tumor vaccines have targeted this devastating condition. Recent clinical trials involving immunotherapy, specifically dendritic cell (DC) based vaccines, have shown promising results. Overall, these vaccines are well tolerated with few documented side effects. In many patients receiving vaccines, tumor progression was delayed and the median overall survival of these patients was prolonged. Despite these encouraging results, several factors have limited the efficacy of DC vaccines. Here we discuss the potential of DC vaccines as adjuvant therapy and current obstacles of generating highly pure and potent DC vaccines in the context of malignant glioma. Taken together, the results from earlier clinical studies justify additional clinical trials aimed at improving the efficacy of DC vaccines.
\end{abstract}

Keywords: malignant glioma, glioblastoma multiforme, vaccine, immunotherapy, dendritic cells

\section{Introduction}

Brain tumors are a diverse group of biologically and pathologically distinct intracranial neoplasms that include tumors of neuroepithelial tissue (gliomas), meningeal tumors, and primary lymphomas of the central nervous system (non-gliomas) (See Buckner et al 2007 for review). Gliomas typically arise from two different cell types in the brain, astrocytes or oligodendrocytes. The most common primary malignant astrocytoma is grade IV (World Health Organization, WHO) malignant glioma or glioblastoma multiforme (GBM). GBM is a highly invasive and aggressive tumor that responds poorly to therapy. Current therapy begins with surgical resection, followed by radiation therapy with concurrent chemotherapy. The median overall survival for these patients is 14.6 months with a 2-year survival rate of $26.5 \%$ (Stupp et al 2005), although the prognosis is much poorer for those patients whose tumor was not completely resected (Yuile et al 2006). As such, novel treatments are desperately needed to improve the outcome for patients with GBM. Recently, several Phase I clinical trials involving immunotherapy of malignant gliomas have shown promising results (Yu et al 2001; Yamanaka et al 2003; Caruso et al 2004; Kikuchi et al 2004; Rutkowski et al 2004; Steiner et al 2004; Yu et al 2004; Liau et al 2005; Yajima et al 2005; Yamanaka et al 2005). Most of these trials have enrolled patients with grade III anaplastic astrocytoma and/or grade IV GBM and have used the antigen presenting cell known as a dendritic cell (DC) as the foundation of these vaccines. In this review we will focus on the safety and efficacy experience to date of DC based vaccines for the treatment of malignant gliomas.

\section{Evidence for anti-glioma immunity}

Malignant gliomas have not generally been considered an appropriate target for immunotherapy. Malignant gliomas produce an immunosuppressive environment 
through multiple mechanisms. GBMs secrete a variety of immunosuppressive cytokines including IL-10, VEGF, and TGF- $\beta$ (Gomez and Kruse 2006) that can inhibit $\mathrm{CD} 8+\mathrm{T}$ cell function and stimulate $\mathrm{T}$ regulatory cells. Patients with GBM are often lymphopenic with particular deficiencies in CD4+ cell numbers and function. Fecci et al reported that, although the peripheral blood CD4+ population is lower in GBM patients compared to normal individuals, the percentage of CD4+ CD25+ FOXP3+ CD45RO+ T regulatory cells (Tregs) is higher in GBM patients (Fecci et al 2006). This study, coupled with another demonstrating that GBM tumors exhibit higher ratios of Tregs in tumor infiltrating lymphocytes (El Andaloussi and Lesniak 2006), indicates that Tregs play an active role in GBM-mediated immunosuppression. Immunosuppressive cytokines secreted by gliomas may also adversely affect the function and phenotype of monocytes (Woiciechowsky et al 1998; Ogden et al 2006). Myeloid-derived suppressor cells have been shown to be involved in promoting tumor progression in animal models of glioma (Prins et al 2002; Graf et al 2005). These suppressor cells and/or immature myeloid cells impair immune function by the direct suppression of $\mathrm{T}$ cells and adversely affect the differentiation of monocytes to dendritic cells (Kusmartsev and Gabrilovich 2006). In agreement with animal models, data from our group and others demonstrate that monocytes isolated from glioblastoma patients were unable to fully differentiate into mature dendritic cells (Ogden et al 2006) (and our own unpublished data). Finally, the brain may physically obstruct immune based therapies as it is considered an immune privileged site due to the restrictive blood brain barrier. However, this perception is now changing as several studies demonstrate active interaction between leukocytes, their immune responses, and the blood brain barrier (Simpson et al 1998; Biernacki et al 2004; Ifergan et al 2008). For example, endothelial cells of the blood brain barrier actively secrete cytokines to recruit CD14+ monocytes and induce migration and differentiation across the barrier in inflammatory conditions (Ifergan et al 2008). In this light, malignant gliomas may be substantially more susceptible to immune modulation than previously thought.

Over the past several years, there has been growing evidence that malignant gliomas are in fact susceptible to targeted stimulation of the immune system. For example, natural specific anti-glioma immunity has been observed in certain animal models (Fecci et al 2003) and in humans. In a study of peripheral blood of GBM patients, Tang et al observed glioma-specific $\mathrm{T}$ cell responses in newly diagnosed patients (Tang et al 2005). They observed CD8+ T cell specific targeting against autologous tumor tissue and an established GBM cell line but not from other tumor types. Ueda et al presented a case report of a patient who survived an anaplastic astrocytoma for twelve years. The population of peripheral $\mathrm{CD} 8+\mathrm{T}$ cells in this patient had high ratios of CD45RA-/CCR7 + memory cells and CD45RA-/CCR7-late effector cells and could produce a CD8+ T cell immune response specific for two glioma-associated antigens, Eph2a and IL-13R $\alpha 2$ (Ueda et al 2007). Finally, most human gliomas contain tumor infiltrating lymphocytes and their presence may have some prognostic value (Bucciero et al 1990). These results suggest that the immunogenicity of GBM in humans is sufficient to induce a tumor specific immune response despite the heterogeneity and anatomic localization of these tumors.

\section{Summary of clinical trials using vaccines for brain tumors}

The anecdotal evidence of immune susceptibility of GBM has led to several early phase clinical trials evaluating the safety and feasibility of brain tumor vaccines ( $Y u$ et al 2001; Kikuchi et al 2002; Yamanaka et al 2003; Caruso et al 2004; Rutkowski et al 2004; Steiner et al 2004; Yu et al 2004; Liau et al 2005; Yajima et al 2005; Yamanaka et al 2005) (Table 1). While most investigators have focused on DC based therapies, others have chosen immunization with other modalities such as free peptides, genetically-modified tumor cells, or expanded autologous T-cells. Differences in antigen and vaccine strategies make comparisons difficult, however, several observations can be made in examining the trials in aggregate. A major concern in immunotherapy is the induction of autoimmune responses within the central nervous system, a potentially devastating side effect. As such, most trials pay particular attention to the induction of autoimmunity. Significantly, no trial has yet reported any evidence of the consistent induction of adverse autoimmunity. The lack of autoimmunity has been accompanied by an overall impressive safety profile with only one Grade 3 or Grade 4 adverse event reported. This patient suffered from peritumoral edema after the second vaccination subsequently controlled by the administration of steroids (Rutkowski et al 2004). The most common reported side effects included fevers, headaches, nausea, and mild erythema and/or induration at the site of injection.

The clinical response to vaccines has varied substantially across all reported trials (Table 1). While every trial reported evidence of clinical responses in some patients, the nature and duration of the response to the vaccines varied significantly. 
Table I Summary of clinical trials using vaccines as therapy for malignant gliomas

\begin{tabular}{|c|c|c|c|c|c|c|c|c|c|c|c|}
\hline $\begin{array}{l}\text { Clinical } \\
\text { trial }\end{array}$ & $\begin{array}{l}\text { Trial } \\
\text { stage }\end{array}$ & Cohort $^{a}$ & $\begin{array}{l}\text { Antigen } \\
\text { source }^{\mathrm{b}}\end{array}$ & Adjuvant $^{c}$ & Dose & Frequency & $\begin{array}{l}\text { \# of } \\
\text { vaccines }\end{array}$ & Route $^{d}$ & Safetye & $\begin{array}{l}\text { Immune } \\
\text { outcomes }\end{array}$ & $\begin{array}{l}\text { Clinical } \\
\text { outcomes }^{\mathrm{g}}\end{array}$ \\
\hline Yu et al & Phase I & $\begin{array}{l}N=9 \text { Mixed, } \\
\text { ND }\end{array}$ & $\begin{array}{l}\text { Peptides } \\
\text { derived } \\
\text { from ACTC }\end{array}$ & IDC & $10^{6} \mathrm{DC}$ & 2 wks & 3 & s.c. & ++ & $\begin{array}{l}\text { ISR, CTL, } \\
\text { TIL }\end{array}$ & $\begin{array}{l}\text { MS: } 455 \text { days } \\
\text { vs } 257 \text { days }\end{array}$ \\
\hline $\begin{array}{l}\text { Steiner } \\
\text { et al }\end{array}$ & $\begin{array}{l}\text { Pilot } \\
\text { Study }\end{array}$ & $\begin{array}{l}N=23 \\
\text { GBM, ND? }\end{array}$ & ACTC & $\begin{array}{l}\text { Newcastle } \\
\text { disease } \\
\text { virus }\end{array}$ & $\begin{array}{l}10^{7} \text { Tumor } \\
\text { cells }\end{array}$ & $\begin{array}{l}\text { Ist } 4: 3 \text { wks } \\
\text { 2nd } 4: 4 \text { wks }\end{array}$ & 8 & i.d. & ++ & $\begin{array}{l}\text { ISR, DTH, } \\
\text { CTL,TIL }\end{array}$ & $\begin{array}{l}\text { MS: } 100 \\
\text { vs } 49 \text { wks }\end{array}$ \\
\hline $\begin{array}{l}\text { Yamanaka } \\
\text { et al }\end{array}$ & Phase I/II & $\begin{array}{l}\mathrm{N}=10 \\
\text { Mixed, } \\
\text { recurrent }\end{array}$ & ATL & $\mathrm{IDC}+\mathrm{KLH}$ & $\begin{array}{l}10-32 \times 10^{6} \\
\mathrm{DC}\end{array}$ & 3 wks & Up to 10 & i.d.or i.t. & ++ & $\begin{array}{l}\text { ISR, DTH, } \\
\text { CTL,TIL }\end{array}$ & $2 P R$ \\
\hline $\begin{array}{l}\text { Rutkowski } \\
\text { et al }\end{array}$ & Phase I & $\begin{array}{l}\mathrm{N}=12 \\
\text { Mixed, } \\
\text { recurrent }\end{array}$ & ATL & MDC & $\begin{array}{l}2-4 \times 10^{6} \\
D C\end{array}$ & $\begin{array}{l}\text { I wk } \\
2 \text { wks } \\
4 \text { wks }\end{array}$ & $2-7$ & i.d. & ++ & DTH & $\begin{array}{l}2 \text { CCR } 2 \text { PR } \\
\text { or SD }\end{array}$ \\
\hline Yu et al & Phase I & $\begin{array}{l}N=14 \\
\text { Mixed, both }\end{array}$ & ATL & IDC & $10^{7}-10^{8} \mathrm{DC}$ & 2 wks & 3 & s.c. & ++ & $\begin{array}{l}\text { ISR, CTL, } \\
\text { TIL }\end{array}$ & $\begin{array}{l}\text { MS: } 133 \text { wks } \\
\text { vs } 30 \text { wks }\end{array}$ \\
\hline $\begin{array}{l}\text { Caruso } \\
\text { et al }\end{array}$ & Phase I & $\begin{array}{l}\mathrm{N}=9 \text { Mixed, } \\
\text { recurrent }\end{array}$ & $\begin{array}{l}\text { Primary } \\
\text { tumor RNA }\end{array}$ & IDC & $\begin{array}{l}0.5 \times 10^{7} \\
D C \text { (i.d.) } \\
0.5-5 \times 10^{7} \\
\text { DC (i.v.) }\end{array}$ & Bi-wk & 6 & $\begin{array}{l}\text { i.d. and } \\
\text { i.v. }\end{array}$ & ++ & $\begin{array}{l}\text { No CTL } \\
\text { observed }\end{array}$ & $2 \mathrm{SD}$ I PR \\
\hline $\begin{array}{l}\text { Kikuchi } \\
\text { et al }\end{array}$ & Phase I & $\begin{array}{l}\mathrm{N}=15 \\
\text { Mixed, } \\
\text { recurrent }\end{array}$ & ACTC & $\begin{array}{l}\text { MDC+ } \\
\text { IL-I2 }\end{array}$ & $\begin{array}{l}3.6-32.3 \times \\
10^{6} \text { Fused } \\
\text { Tumor } \\
\text { Cell/DC }\end{array}$ & 2 wks & Up to 6 & i.d. & ++ & $\begin{array}{l}\text { ISR, CTL, } \\
\text { TIL }\end{array}$ & $4 \mathrm{PR}$ \\
\hline Liau et al & Phase I & $\begin{array}{l}\mathrm{N}=24 \mathrm{GBM}, \\
\text { both }\end{array}$ & $\begin{array}{l}\text { Peptides } \\
\text { derived } \\
\text { from ACTC }\end{array}$ & IDC & $\begin{array}{l}1,5, \text { or } \\
10 \times 10^{6} \\
D C\end{array}$ & Bi-wk & 3 & i.d. & ++ & $\begin{array}{l}\text { ISR, CTL, } \\
\text { TIL }\end{array}$ & $\begin{array}{l}\text { MS:35.8 mo. } \\
\text { vs I } 8.3 \text { mo. } \\
\text { I near CR }\end{array}$ \\
\hline $\begin{array}{l}\text { Yamanaka } \\
\text { et al }\end{array}$ & Phase I/II & $\begin{array}{l}\mathrm{N}=24 \\
\text { Mixed, } \\
\text { recurrent }\end{array}$ & ATL & $\begin{array}{l}\text { MDC+ } \\
\text { KLH or } \\
\text { OK-432 }\end{array}$ & $\begin{array}{l}\mathrm{I}-32 \times 10^{6} \\
\mathrm{DC}\end{array}$ & 3 wks & Up to 10 & $\begin{array}{l}\text { i.d. or } \\
\text { i.t. }\end{array}$ & ++ & $\begin{array}{l}\text { ISR, DTH, } \\
\text { CTL }\end{array}$ & $\begin{array}{l}\text { Survival: } \\
23.5 \% \text { at } \\
2 \text { yrs. vs } 3.7 \%\end{array}$ \\
\hline $\begin{array}{l}\text { Yajima } \\
\text { et al }\end{array}$ & Phase I & $\begin{array}{l}\mathrm{N}=25 \\
\text { Mixed, both }\end{array}$ & $\begin{array}{l}\text { Manufact- } \\
\text { ured } \\
\text { peptides }\end{array}$ & $\begin{array}{l}\text { Monatanide } \\
\text { ISA 5I }\end{array}$ & $\begin{array}{l}3 \mathrm{mg} / \mathrm{ml} \\
\text { peptides + } \\
\text { adjuvant }\end{array}$ & $\begin{array}{l}\text { Wk or } \\
\text { Bi-wk }\end{array}$ & $\begin{array}{l}\text { Up to } \\
24 ?\end{array}$ & s.c. & ++ & $\begin{array}{l}\text { ISR, DTH, } \\
\text { CTL }\end{array}$ & $\begin{array}{l}5 \text { PR } 8 \text { SD } \\
8 \text { PD }\end{array}$ \\
\hline
\end{tabular}

aClinical trials involved patients with malignant glioma (grade III anaplastic astrocytoma or grade IV glioblastoma multiforme (GBM) or both (mixed)) and were newly diagnosed (ND) or had recurrent disease. Caruso et al enrolled pediatric patients with various brain tumors.

${ }^{\mathrm{b}} \mathrm{ACTC}$, autologous cultured tumor cells; ATL, autologous tumor lysates.

cMost studies involved immature (IDC) or mature (MDC) dendritic cells. Most DC culture conditions involved a 7 day culture system of adherent PBMCs with medium containing $10 \%$ fetal calf serum or 1\%-10\% autologous human serum plus GM-CSF and IL-4. When MDCs were used, methods were consistent with possible DC maturation but not reported on every patient.

i.d, intra-dermal; i.t, intra-tumor; i.v, intra-venous; s.c, sub-cutaneous.

${ }^{\mathrm{e}}++$ indicates no grade III or grade IV adverse events or no evidence of autoimmunity. Rutkowski et al report I patient having Grade IV neurological deficits resulting from peri-tumoral edema.

'Reported observations include ISR, injection site reaction (induration, erythema); DTH, delayed type hypersensitivity; CTL, cytotoxic T lymphocyte (evidence of specific antitumor T cell responses); TILs, tumor infiltrating lymphocytes (confirmed presence).

gMS, median overall survival; PR, partial response; CCR, complete continous response; SD, stable disease; PD, progressive disease; CR complete response.

Of the five trials reporting survival data, each of the patient groups receiving vaccines had a prolonged overall median survival (an average of the trials of about a 2.5 -fold increase) or a higher percentage surviving at 2 years (Yu et al 2001; Steiner et al 2004; Yu et al 2004; Liau et al 2005; Yamanaka et al 2005). In addition, two of the trials report that some patients were in complete remission beyond the end of the study (Rutkowski et al 2004; Liau et al 2005). Interestingly, many of the investigators reported that they were not always able to correlate overall survival to the cellular immune responses observed in the patient. The data from these trials also indicate that there may be a sub-population of patients who will respond well to these vaccines. Overall, the trials have documented a favorable safety profile and in some cases 
improved survival, however, no correlative biomarker or immune function has predicted clinical responses.

\section{Obstacles to optimal GBM vaccine efficacy}

Beyond the shared characteristics of these trials, there exists a lack of consensus of many aspects of this approach. There is a significant need for standardization of vaccine preparations to collectively improve therapeutic response. Here, we will discuss several aspects of vaccine development that need more focused attention in order to improve the potency of this approach. Since most trials use DCs as an adjuvant for vaccines, we will specifically focus on issues relating to DC-based vaccines.

\section{Dendritic cell culture}

The primary goal of immunotherapy is the induction of anti-tumor immunity while minimizing autoimmunity. The appropriate activation of naïve and memory $\mathrm{T}$ cells, NK and NKT cells are essential to directing a beneficial anti-tumor immune response. The cells most capable of activating these and other immune effector cells are DCs (for review see O'Neill et al 2004; Panoskaltsis et al 2004). DCs arise from both lymphoid and myeloid progenitors within the bone marrow. CD14+ monocytes can give rise to immature DCs as they migrate from the blood stream to peripheral tissues (Pickl et al 1996). Immature DC are characterized by their ability to induce a tolerizing immune phenotype through activation of regulatory $\mathrm{T}$ cells, and inability to stimulate naïve or antigen specific memory $\mathrm{T}$ cells (Dhodapkar and Steinman 2002; Wakkach et al 2003). In the peripheral tissues, immature DCs sample their environment via phagocytosis and macropinocytosis. The presence of toll-like receptor (TLR) ligands provided by microorganisms or stimulating cytokines induces a transformation into fully activated mature DCs, with resulting presentation of the internalized entities on appropriate MHC molecules. Mature DCs express high levels of Class I and Class II molecules, altered chemokine and galectin family (Dietz et al 2000; Bax et al 2007) expression, co-stimulatory markers CD80 and CD86, and the immunoglobulin CD83 (Zhou and Tedder 1995). They migrate to draining lymph nodes and activate innate and adaptive immune responses. To stimulate a similar response in brain cancer patients, DC progenitors (usually monocytes) are cultured to generate DC and pulsed with proteins associated with tumors to generate an anti-tumor immune response.

Two methods are currently being investigated to develop antigen-loaded and fully activated DCs. One method is to target DCs in vivo by targeting antigens to DC cell surface receptors such as the mannose receptor, CD205, or DC-SIGN (see Tacken et al for review (Tacken et al 2007)). After antigens are administered, DC maturation signals like TLR ligands, activators of $\mathrm{CD} 40$, or $\alpha$-galactosylceramide are then given systemically (Fujii et al 2003; Bonifaz et al 2004; van Duin et al 2006; Lapteva et al 2007). The other method involves ex vivo culture of DCs where antigens are loaded and DCs are matured in the culture dish before administration. While each method has its own advantages, the scarcity of DC in vivo and the difficulty in targeting and activation limit the capacity for in vivo targeting whereas the ability to isolate and differentiate CD14+ monocytes to DCs from whole blood provides an abundant source of DCs (Pickl et al 1996; Zhou and Tedder 1996). Therefore, most clinical trials manipulate DC through ex vivo culture to assure accurate antigen delivery and DC activation.

Most culture systems used in clinical trials have been adapted from the standard 10-day culture method of adherent peripheral blood mononuclear cells in a base media containing serum, either fetal calf serum or autologous human serum, with the addition of GM-CSF and IL-4 (Sallusto and Lanzavecchia 1994; Kiertscher and Roth 1996; Jonuleit et al 1997). DCs are recovered, incubated with antigen, and then aliquoted for individual doses. If the DCs are not cultured in additional inflammatory cytokines or toll-like receptor ligands, the method results in immature DCs. While antigen uptake is enhanced in immature DCs, they can to induce tolerance if not fully activated (Steinman and Nussenzweig 2002). For example, in vivo injection of immature DCs loaded with influenza matrix peptide led to antigen specific silencing of effector cells (Dhodapkar and Steinman 2002). Also, in a study involving patients with stage IV melanoma, de Vries et al directly compared the efficacy vaccines using immature or mature DCs in inducing an immune response (de Vries et al 2003). They reported that delayed-type hypersensitivity reactions and humoral responses to KLH were observed in patients receiving mature DCs whereas those receiving immature DCs had no DTH reactions and few KLH responses. These responses correlated with improved clinical outcomes for patients receiving mature DCs (de Vries et al 2003). Five of the eight GBM clinical trials that used DC vaccines administered immature DCs (see Table 1, Adjuvants). The other three trials included maturation stimuli in their culturing methods. Since only fully activated, mature DCs are able to migrate to lymph nodes and optimally promotes $\mathrm{T}$ cell activation, culturing mature DCs should strongly be encouraged for clinical trial use. 
Unfortunately, there is significant variability in the reporting of the phenotype of DCs used for vaccines. We agree with Figdor et al (2004) that as part of the standardization and release criteria for DC vaccines, full DC phenotypes should be reported for each patient. For example, when monocyte-derived mature DCs are administered, the expression of maturation markers like CD83, CD80, and CD86 should be measured. With this information, the purity and potency of DC for each individual can be assessed to ensure the reproducible quality of the vaccine. Such properties may be useful in understanding the immunogenicity and clinical efficacy.

Due to the variety of culturing conditions in the reported trials, standardized protocols to reliably manufacture mature DCs are necessary for future clinical trials. This protocol must be able to yield reproducible results and satisfy any regulatory guidelines that restrict, or in some cases disallow, governing the use of reagents for DC culture. Moreover, it is becoming recognized that a patient's disease status may impact the outcome of culturing patient-derived monocytes. For example, Ogden et al report that monocytes isolated from GBM patients are phenotypically abnormal and have an impaired ability to differentiate into DCs (Ogden et al 2006). In agreement with this report, recent data from our laboratory indicate that cultured monocytes isolated from GBM patients are resistant to DC culture using classical protocols and result in mixed populations of immature and mature DC (Dietz unpublished data). We found that DC maturation is highly dependent on individual donors, base media and culture conditions, and the disease status of patient sub-groups. While CD80 expression was consistent in each culture condition, CD83 expression was much more sensitive to the differing conditions. CD83 is likely an important cell surface marker for mature DCs because it behaves like a co-stimulatory signal by priming naïve CD8+ T cells, induces their antigenspecific expansion and prolongs their survival (Hirano et al 2006; Aerts-Toegaert et al 2007). In summary, improvements to DC vaccines is a critical step toward the optimization of vaccine strategies for GBM and further improvement to these vaccines will require close attention and reporting of the DC phenotypes used in the vaccine.

\section{Antigen source and delivery}

For cancer vaccines to be effective, the source of tumor antigen must also be carefully considered. Autologous tumor tissue, cultured tumor cells, whole tumor RNA, and tumor peptides have all been used as antigen sources. Primary tumor lysates or whole tumor RNA generated by processing resected tumors are the most common antigen sources and offer the advantage of providing multiple tumor antigens. However, tumor protein lysates and RNA present three problems: (1) lysates or RNA made from tumor tissue are often in limited quantities; (2) they are an inconsistent source of antigenic material and can make immune monitoring problematic and (3) they may often be contaminated with non-target cells such as normal brain, endothelium, or cells of hematopoetic origin. Alternatively, tumor cells may be cultured to expand the amount of antigen source and reduce the amount of contaminating material. While most researchers have used media supplemented with ten percent fetal calf serum, recent evidence suggests that GBM cells cultured in this method are phenotypically and biologically different than the primary tumor from which they are derived (Lee et al 2006). However, GBM cells grown in serum-free medium supplemented with neurotrophic factors, and EGF and FGF, grow as ball-shaped structures called neurospheres, and maintain vital characteristics of the primary tumor, including gene expression profiles, tumorigenicity, and genetic abnormalities (Lee et al 2006; de Witt Hamer et al 2008). In addition, these neurospheres contain a higher density of tumor stem cells that may elicit a better immune response in vivo than cells grown as a monolayer in serum containing medium possibly due to an increase in expression of MHC Class II molecules and/or co-stimulatory molecules (Pellegatta et al 2006). Additionally, by direct targeting of tumor stem cells, the vaccine might eradicate cells most critical to the proliferation and invasion of the tumor. The observations in these studies and in others highlight the importance of appropriate cell culture systems and that these systems should be carefully developed to optimally reflect the phenotype and biology of the cells in vivo (Debnath et al 2003; Zhang et al 2005; Gustafson et al 2006). While culturing tumor cells can be advantageous over the use of the primary tumor as an antigen, it may not be practical because of the time needed to generate enough cells for a vaccine or lack of clinical grade reagents needed for culturing. As culturing systems become more advanced, cultured tumor cells may provide sufficient material, enriched for tumor antigens, and contain less contaminating material thereby making them a suitable antigen source for future vaccine trials.

Defined tumor associated antigens (TAA), whether it be in the form of peptides, RNA, or DNA provide convenience of using "off the shelf" reagents and allow for immune monitoring of specific TAAs. However, the potential of tumor antigen escape and the limited repertoire of using defined 
antigens create inherent problems of their own. Peptides have additional problems because they are human leukocyte antigen (HLA) class I or II restricted, and consequently, restrict patient enrollment into clinical trials, and class I peptides are insufficient to generate a CD4+ T helper response which are required for optimal orchestration of effective and sustained anti-tumor immunity (Knutson and Disis 2005).

The optimal method for antigen delivery to DC is still controversial. However, a manuscript identifying the current consensus regarding an optimal antigen source concluded; "the most constitutive and prolonged MHC I presentation would likely result from processing of endogenously produced proteins located in the cytoplasm; like other cells, DC present self- or virus-derived endogenous antigens generated via proteasome degradation of newly synthesized ubiquitinated proteins." (Katoh et al 2003) These expression characteristics limit the methods useful for delivering antigens to viral, DNA or RNA based delivery methods. Of these, RNA delivery of tumor-specific (TSA) and/or associated antigens (TAA) has proven to be the most reliable, efficient and stimulatory method available (Cabuy and de Ridder 2001; Liu et al 2004; Ozawa et al 2004).

In summary, there has been no consensus in the field of DC vaccines for the optimal antigen source. Five of the 10 trials listed in Table 1 (see Antigen Source column) use autologous tumor lysate or tumor-derived RNA, 3 trials used peptides ( 1 used manufactured peptides, and 2 derived from cultured cells), one trial used autologous tumor cells infected with a virus and one trial fused tumor cells to DCs. Four of the 10 trials used culturing methods containing animal products (ie, fetal calf/bovine serum) in their culturing schemes. Animal serum has several disadvantages in clinical use including inconsistency between lots, potential introduction of adventitious organisms and alterations in the underlying biology of the tumor. Since the antigen source and delivery systems are crucial components in manufacturing an effective vaccine, the success of future clinical trials will require further research to address these concerns. Feasibility issues will also certainly need to be considered in the context of concurrent therapy for brain tumors.

\section{$D C$ vaccination as an adjuvant therapy}

In the clinical setting, DC vaccines have essentially been used as adjuvant therapy after surgical resection of the embedded tumor. So far, it appears that the use of DC vaccines in the context of concurrent chemotherapy is feasible and has not resulted in additional toxicity. There are now reports demonstrating that appropriate timing of the vaccination can improve the outcome of GBM patients by either sensitizing tumor cells to further chemotherapy or synergize with chemotherapy to delay tumor progression and prolong survival (Wheeler et al 2004; Liu et al 2005). As such, DC vaccines could be used as an adjuvant therapy after surgical resection of the tumor. Further considerations are needed to determine whether there are optimal times of vaccination after surgery and to determine dosing schedules to best augment an anti-tumor response with current cycles of chemotherapy.

Patients receiving treatment for glioblastoma are often given steroids like dexamethasone or prednisone to treat tumor-associated edema. Dexamethasone is a widely used reagent that has well documented immunosuppressive capabilities (Rhen and Cidlowski 2005). Dexamethasone has been shown to adversely affect the function of monocyte-derived DCs (Woiciechowsky et al 1998; van den Heuval et al 1999; Ogden et al 2006) and can enhance DCs mediated tolerance. In the context of malignant gliomas, some have reported that the presence of steroids may directly interfere with the vaccine itself (by reducing manufacturing efficiency) (Rutkowski et al 2004) or that patients on steroids do not fare as well as those who are on little or no steroids (Yajima et al 2005). These observations highlight the need for further analysis of the effects of dexamethasone on immune function and anti-tumor immunity. For future clinical trials, the coordination of immunotherapy with steroid treatment and the impact of dexamethasone on the immune status of the patient are important additional factors to be considered.

\section{Immune monitoring}

Since tumor destruction is mediated secondarily to the generation of an immune response by the vaccines, immune monitoring has been a major component of prior GBM vaccine studies. Monitoring the biologic activity of the vaccine should be given as much emphasis as the clinical outcome, particularly if there is an interest in further vaccine optimization. However, immune monitoring remains a significant challenge for a number of reasons. Foremost amongst these reasons are (1) significant variability observed in in vitro functional T cell assays, (2) a lack of knowledge of what to measure, and (3) high costs in terms of labor and materials for assay development and validation (Knutson et al 2006). The main goal of immune monitoring is to establish an immunologic correlate of clinical outcomes (Britten et al 2008). These correlations have been elusive in all cancer settings and brain cancer vaccines are no exception. Of those trials discussed in this review, the best correlation was 
described by Liau and colleagues, who showed that survival was positively correlated with the magnitude of T cell infiltration into the tumors (Liau et al 2005). Despite that, it is clear that brain cancer vaccines are immunogenic and many of the patients enrolled in the clinical trials demonstrated elevated immune responses following vaccination.

The primary reason for the lack of correlations between the immune response to vaccine and clinical outcomes is that the trials are not adequately designed to detect these types of correlations. Rather, the trials are typically designed to test for feasibility and safety. Kielholz and colleagues recently published an outstanding treatise discussing the strengths and weaknesses of immune monitoring which included estimates of sample sizes that are required to detect such clinical correlations. It is clear from their analysis that correlations between immunity and clinical responses (regressions and survival) are likely to only be borne out in advanced efficacy trials rather than pilot, safety, and feasibility trials, where a considerably higher number of patients are enrolled (Keilholz et al 2006). Despite that, however, immune monitoring should be carefully developed in the early trials perhaps as recently delineated in a paradigm by the Cancer Vaccine Clinical Trial Working Group (CVCTWG) (Hoos et al 2007). This paradigm suggests that, given the acceptable safety profiles of cancer vaccines, early trials should be designed to test the feasibility that a candidate vaccine elicits either a biologic (ie, immune) or a clinical response in the target population. Once validated, these response assessments can then be correlated in future efficacy trials.

\section{Future directions and conclusions}

The recent trials involving DC vaccination therapy for malignant gliomas have provided the groundwork in which future clinical trials can continue to improve. It is now encouraging to see that these trials are beginning to move to Phase II. For example, Dr Linda Liau, in conjunction with Northwest Biotherapeutics, Inc. (Seattle, WA), are currently enrolling patients with GBM for a multi-center Phase II to test the efficacy of their autologous DC based vaccine, $\mathrm{DCVax}^{\circledR}$-Brain (Northwest Biotherapeutics 2007). The target enrollment for the trial is 141 newly diagnosed patients. Patients will undergo surgery, radiation and concomitant chemotherapy. The primary endpoint for the trial is patient survival with no disease progression and the second endpoint is overall survival. This Phase II trial follows their first trial in which GBM patients receiving the vaccine had a median survival of 35.8 months compared to 18.3 months for the control group with some patients surviving more than
3 years with no evidence of tumor recurrence (Liau et al 2005; Northwest Biotherapeutics 2007). The Phase II trial will add more vaccine doses (up to 10 over $2 \frac{1}{2}$ years) than the three doses given in the Phase I trial. The patient accrual is expected to end soon and the results of this trial will be highly anticipated.

Novel therapies are desperately needed for the treatment of malignant gliomas. Since DC vaccines have shown a very favorable safety profile and that they are likely to work in conjunction with current therapeutic protocols, the prospects of using vaccines as a standard of care as adjuvant therapy looks promising. But until we can correlate patient immune responses to clinical outcomes, it is likely necessary to focus on six month progression free survival as the primary endpoint for clinical trials. As the obstacles to the efficiency of DC vaccines are removed and the standardization of vaccines moves forward, these vaccines are likely to become a viable option for those patients facing difficult treatments.

\section{Acknowledgments}

ABD would like to acknowledge support from the Mayo Foundation and a grant from the National Cancer Institute (CA108961).

\section{Disclosures}

The authors have no conflicts of interest to disclose.

\section{References}

Aerts-Toegaert C, Heirman C, et al. 2007. CD83 expression on dendritic cells and $\mathrm{T}$ cells:Correlation with effective immune responses. Eur J Immunol, 37:686-95.

Bax M, García-Vallejo JJ, et al. 2007. Dendritic cell maturation results in pronounced changes in glycan expression affecting recognition by siglecs and galectins. J Immunol, 179:8216-24.

Biernacki K, Prat A, et al. 2004. Regulation of cellular and molecular trafficking across human brain endothelial cells by Th1- and Th2-polarized lymphocytes. J Neuropathol Exp Neurol, 63:223-32.

Bonifaz LC, Bonnyay DP, et al. 2004. In vivo targeting of antigens to maturing dendritic cells via the DEC-205 receptor improves T cell vaccination. $J$ Exp Med, 199:815-24.

Britten CM, Janetzki S, et al. 2008. Toward the harmonization of immune monitoring in clinical trials: Quo vadis? Cancer Immunol Immunother, 57:285-8.

Bucciero A, Vizioli L, et al. 1990. Prognostic significance of lymphoid infiltration in cerebral malignant gliomas. J Neurosurg Sci, 34:145-8.

Buckner JC, Brown PD, et al. 2007. Central nervous system tumors. Mayo Clin Proc, 82:1271-86.

Cabuy E, de Ridder L. 2001. Telomerase activity and expression of telomerase reverse transcriptase correlated with cell proliferation in meningiomas and malignant brain tumors in vivo. Virchows Archiv, 439:176-84.

Caruso, DA, Orme, LM, et al. 2004. Results of a phase 1 study utilizing monocyte-derived dendritic cells pulsed with tumor RNA in children and young adults with brain cancer. Neuro Oncol, 6:236-46.

de Vries IJ, Lesterhuis WJ, et al. 2003. Maturation of dendritic cells is a prerequisite for inducing immune responses in advanced melanoma patients. Clin Cancer Res, 9:5091-100. 
de Witt Hamer PC, van Tilborg AA, et al. 2008. The genomic profile of human malignant glioma is altered early in primary cell culture and preserved in spheroids. Oncogene, 27:2091-6.

Debnath J, Muthuswamy SK, et al. 2003. Morphogenesis and oncogenesis of MCF-10A mammary eptihelial acini grown in three-dimensional basement membrane cultures. Methods, 30:256-68.

Dhodapkar MV, Steinman, RM. 2002. Antigen-bearing immature dendritic cells induce peptide-specific CD8(+) regulatory T cells in vivo in humans. Blood, 100:174-7.

Dietz AB, Bulur PA, et al. 2000. Maturation of human monocyte-derived dendritic cells studied by microarray hybridization. Biochem Biophys Res Commun, 275:731-8.

El Andaloussi A, Lesniak, MS. 2006. An increase in CD4+ CD25+ FOXP3+ regulatory $\mathrm{T}$ cells in tumor-infiltrating lymphocytes of human glioblastoma mutliforme. Neuro-oncol, 8:234-43.

Fecci PE, Mitchell DA, et al. 2003. The history, evolution, and clinical use of dendritic cell-based immunization strategies in the therapy of brain tumors. J Neurooncol, 64:161-76.

Fecci PE, Mitchell DA, et al. 2006. Increased regulatory T-cell fraction amidst a diminished CD4 compartment explains cellular immune defects in patients with malignant glioma. Cancer Res, 66:3294-302.

Figdor, CG, de Vries IJ, et al. 2004. Dendritic cell immunotherapy:mapping the way. Nat Med, 10:475-80.

Fujii S, Shimizu K, et al. 2003. Activation of natural killer T cells by alpha-galactosylceramide rapidly induces the full maturation of dendritic cells in vivo and thereby acts as an adjuvant for combined CD4 and CD8 $\mathrm{T}$ cell immunity to a coadministered protein. $J$ Exp Med, 198:267-79.

Gomez GG, Kruse, CA. 2006. Mechanisms of malignant glioma immune resistance and sources of immunosuppression. Gene Ther Mol Biol, 10:133-46.

Graf MR, Sauer JT, et al. 2005. Tumor infiltration by myeloid suppressor cells in response to $\mathrm{T}$ cell activation in rat gliomas. J Neurooncol, 73:29-36.

Gustafson MP, Xu C, et al. 2006. Regulation of cell proliferation in a stratified culture system of epithelial cells from prostate tissue. Cell Tissue Res, 325:263-76.

Hirano N, Butler MO, et al. 2006. Engagement of CD83 ligand induces prolonged expansion of CD8+ T cells and preferential enrichment for antigen specificity. Blood, 107:1528-36.

Hoos A, Parmiani G, et al. 2007. A clinical development paradigm for cancer vaccines and related biologics. J Immunother, 30:1-15.

Ifergan I, Kebir H, et al. 2008. The blood-brain barrier induces differentiation of migrating monocytes into Th17-polarizing dendritic cells. Brain, 131:785-99.

Jonuleit H, Kuhn U, et al. 1997. Pro-inflammatory cytokines and prostaglandins induce maturation of potent immunostimulatory dendritic cells under fetal calf serum-free conditions. Eur J Immunol, 27:3135-42.

Katoh M, Wilmotte R, et al. 2003. Survivin in brain tumors:an attractive target for immunotherapy. J Neurooncol, 64:71-6.

Keilholz U, Martus P, et al. 2006. Immune monitoring of T-cell responses in cancer vaccine development. Clin Cancer Res, 12:2346s-52s.

Kiertscher SM, Roth, MD. 1996. Human CD14+ leukocytes acquire the phenotype and function of antigen-presenting dendritic cells when cultured in GM-CSF and IL-4. J Leukoc Biol, 59:208-18.

Kikuchi T, Akasaki Y, et al. 2004. Vaccination of glioma patients with fusions of dendritic and glioma cells and recombinant human interleukin 12. J Immunother, 27:452-9.

Kikuchi T, Akasaki Y, et al. 2002. Intratumoral injection of dendritic and irradiated glioma cells induces anti-tumor effects in a mouse brain tumor model. Cancer Immunol Immunother, 51:424-30.

Knutson KL, dela Rosa C, et al. 2006. Laboratory analysis of T-cell immunity. Front Biosci, 11:1932-44.

Knutson KL, Disis, ML. 2005. Tumor antigen-specific T helper cells in cancer immunity and immunotherapy. Cancer Immunol Immunother, $54: 721-8$.
Kusmartsev S, Gabrilovich, DI. 2006. Role of immature myeloid cells in mechanisms of immune evasion in cancer. Cancer Immunol Immunother, 55:237-45.

Lapteva N, Seethammagari MR, et al. 2007. Enhanced activation of human dendritic cells by inducible CD40 and Toll-like receptor-4 ligation. Cancer Res, 67:10528-37.

Lee J, Kotliarova S, et al. 2006. Tumor stem cells derived from glioblastomas cultured in bFGF and EGF more closely mirror the phenotype and genotype of primary tumors than do serum-cultured cell lines. Cancer Cell, 9:391-403.

Liau LM, Prins RM, et al. 2005. Dendritic cell vaccination in glioblastoma patients induces systemic and intracranial T-cell responses modulated by the local central nervous system tumor microenvironment. Clin Cancer Res, 11:5515-25.

Liu G, Akasaki Y, et al. 2005. Cytotoxic T cell targeting of TRP-2 sensitizes human malignant glioma to chemotherapy. Oncogene, 24:5226-34.

Liu G, Yu JS, et al. 2004. AIM-2:a novel tumor antigen is expressed and presented by human glioma cells. J Immunother, 27:220-6.

Northwest Biotherapeutics, Website 2007. DCVax ${ }^{\circledR}$ - Brain Phase II Clinical Trial.

O'Neill DW, Adams S, et al. 2004. Manipulating dendritic cell biology for the active immunotherapy of cancer. Blood, 104:2235-46.

Ogden AT, Horgan D, et al. 2006. Defective receptor expression and dendritic cell differentiation of monocytes in glioblastomas. Neurosur, 59:902-10.

Ozawa T, Gryaznov SM, et al. 2004. Antitumor effects of specific telomerase inhibitor GRN163 in human glioblastoma xenografts. Neuro Oncol, 6:218-26.

Panoskaltsis N, Reid CD, et al. 2004. Immune modulation with dendritic cells. Transfus Med, 14:81-96.

Pellegatta S, Poliani PL, et al. 2006. Neurospheres enriched in cancer stem-like cells are highly effective in eliciting a dendritic cellmediated immune response against malignant gliomas. Cancer Res, 66:10247-52.

Pickl WF, Majdic O, et al. 1996. Molecular and functional characteristics of dendritic cells generated from highly purified CD14+ peripheral blood monocytes. J Immunol, 157:3850-9.

Prins RM, Scott GP, et al. 2002. Irradiated tumor cell vaccine for treatment of an established glioma. II. Expansion of myeloid suppressor cells that promote tumor progression. Cancer Immunol Immunother, 51:190-9.

Rhen T, Cidlowski JA. 2005. Antiinflammatory action of glucocorticoids-new mechanisms for old drugs. N Engl J Med, 353:1711-23.

Rutkowski S, De Vleeschouwer S, et al. 2004. Surgery and adjuvant dendritic cell-based tumour vaccination for patients with relapsed malignant glioma, a feasibility study. Br J Cancer, 91:1656-62.

Sallusto F, Lanzavecchia, A. 1994. Efficient presentation of soluble antigen by cultured human dendritic cells is maintained by granulocyte/macrophage colony-stimulating factor plus interleukin 4 and downregulated by tumor necrosis factor alpha. J Exp Med, 179:1109-18.

Simpson JE, Newcombe J, et al. 1998. Expression of monocyte chemoattractant protein-1 and other beta-chemokines by resident glia and inflammatory cells in multiple sclerosis lesions. J Neuroimmunol, 84:238-49.

Steiner HH, Bonsanto MM, et al. 2004. Antitumor vaccination of patients with glioblastoma multiforme:a pilot study to assess feasibility, safety, and clinical benefit. $J$ Clinl Oncol, 22:4272-81.

Steinman RM, Nussenzweig, MC. 2002. Avoiding horror autotoxicus:The importance of dendritic cells in peripheral T cell tolerance. Proc Natl Acad Sci U S A, 99:351-8.

Stupp R, Mason WP, et al. 2005. Radiotherapy plus concomitant and adjuvant temozolomide for glioblastoma. $N$ Engl J Med, 352:987-96.

Tacken PJ, de Vries IJ, et al. 2007. Dendritic-cell immunotherapy: from ex vivo loading to in vivo targeting. Nat Rev Immunol, 7:790-802.

Tang J, Flomenberg P, et al. 2005. Glioblastoma patients exhibit circulating tumor-specific CD8+ T cells. Clin Cancer Res, 11:5292-9.

Ueda R, Low KL, et al. 2007. Spontaneous immune responses against glioma-associated antigens in a long term survivor with malignant glioma. J Transl Med, 5:68. 
van den Heuval MM, van Beek NM, et al. 1999. Glucocorticoids modulate the development of dendritic cells from blood precursors. Clin Exp Immunol, 115:577-83.

van Duin D, Medzhitov R, et al. 2006. Triggering TLR signaling in vaccination. Trends Immunol, 27:49-55.

Wakkach A, Fournier N, et al. 2003. Characterization of dendritic cells that induce tolerance and $\mathrm{T}$ regulatory 1 cell differentiation in vivo. Immunity, 18:605-17.

Wheeler CJ, Das A, et al. 2004. Clinical responsiveness of glioblastoma multiforme to chemotherapy after vaccination. Clin Cancer Res, 10:5316-26.

Woiciechowsky C, Asadullah K, et al. 1998. Diminished monocytic HLA-DR expression and ex vivo cytokine secretion capacity in patients with glioblastoma:Effect of tumor extirpation. J Neuroimmunol, 84:164-71.

Yajima N, Yamanaka R, et al. 2005. Immunologic evaluation of personalized peptide vaccination for patients with advanced malignant glioma. Clin Cancer Res, 11:5900-11.

Yamanaka R, Abe T, et al. 2003. Vaccination of recurrent glioma patients with tumour lysate-pulsed dendritic cells elicits immune responses: results of a clinical phase I/II trial. Br J Cancer, 89:1172-9.
Yamanaka R, Homma J, et al. 2005. Clinical evaluation of dendritic cell vaccination for patients with recurrent glioma:results of a clinical phase I/II trial. Clin Cancer Res, 11:4160-7.

Yu JS, Liu G, et al. 2004. Vaccination with tumor lysate-pulsed dendritic cells elicits antigen-specific, cytotoxic T-cells in patients with malignant glioma. Cancer Res, 64:4973-9.

Yu JS, Wheeler CJ, et al. 2001. Vaccination of malignant glioma patients with peptide-pulsed dendritic cells elicits systemic cytotoxicity and intracranial T-cell infiltration. Cancer Res, 61:842-7.

Yuile P, Dent O, et al. 2006. Survival of glioblastoma patients related to presenting symptoms, brain site and treatment variables. J Clin Neurosci, 13:747-51.

Zhang X, Wang W, et al. 2005. Development of an in vitro multicellular tumor spheroid model using microencapsulation and its application in anticancer screening and testing. Biotechnol Prog, 21:1289-96.

Zhou LJ, Tedder TF. 1995. Human blood dendritic cells selectively express CD83, a member of the immunoglobulin family. J Immunol, 154:3821-35.

Zhou LJ, Tedder TF. 1996. CD14+ blood monocytes can differentiate into functionally mature CD83+ dendritic cells. Proc Natl Acad Sci US A, 93:2588-92. 
